\title{
Determining the Motor Ability Levels of the Preschool Children
}

\author{
Zehra Gozel Tepe ${ }^{1}$ \\ ${ }^{1}$ Faculty of Sport Sciences, Nigde Omer Halisdemir University, Nigde, Turkey \\ Correspondence: Zehra Gozel Tepe, Faculty of Sport Sciences, Nigde Omer Halisdemir University, Nigde, \\ Turkey. E-mail: zehra.gozeltepe@ohu.edu.tr
}

Received: March 6, 2020 Accepted: April 10, 2020 Online Published: April 27, 2020

doi:10.5539/jel.v9n3p73 URL: https://doi.org/10.5539/jel.v9n3p73

\begin{abstract}
In this study, it was aimed to investigate the motor ability levels of the preschool children. The sampling of the study consisted of 46 children ( 22 girls, 24 boys) between the ages of 5-6. Kindergarten Mobile Test (KiMo) was used in determining the motor ability levels of the children. The test consisted of 5 subtests. These were; the shuttle run, standing long jump, one leg stand, flexibility and lateral jumping. Descriptive statistics were used to identify the average, frequency and percentage distributions regarding the motor abilities of the children. The children achieved average and below-average scores at all age groups in the shuttle run, standing long jump, one leg stand, flexibility and lateral jumping and they were incompetent in coordination, endurance and speed as basic motor abilities. As a result, it was determined that the motor abilities of the preschool children were low as of the early years. Performing activities that involve motor abilities inside and outside the school for the preschool children, who spend most of the day in narrow locations with limited movement areas, would support their healthy development in physical, mental and social terms.
\end{abstract}

Keywords: preschool kids, KiMo test, motorability

\section{Introduction}

Motor abilities play an important role in the development of children throughout their lives and are important parts of their physical development (Haywood \& Getchell, 2014). Motor abilities can be reviewed in three different parts: Balance abilities, displacement abilities and abilities that require object control. The ideal time for teaching and developing motor abilities is the early childhood, in other words, the preschool period (Payne \& Isaacs, 2016). Especially the basic movements period, which takes placebetween the ages 2-7, has a different importance since it is the period when the abilities that form the basis of more complex motor programs develop. In these years, children are ready to learn new motor abilities within the rapid development process (Gallahue \& Cleland-Donnelly, 2007). In this age period, development of motor abilities in children increases as they learn abilities such as running, jumping and bouncing. These abilities are permanently used throughout life and play a key role in learning new abilities. However, if children are not given the opportunity to move and try new abilities, their motor ability performances could be affected negatively (Gallahue et al., 2012). If children are not masterly trained in basic life abilities that are preconditions in the active life such as running, jumping and bouncing, they will have limited opportunities to participate in physical activities later in their lives (Stodden, Goodway, Langendorfer, Roberton, Rudisill, Garcia, \& Garcia, 2008).

Children between the ages of 5-6 look forward to do the movements such as running, jumping and bouncing by nature and they have such an energy that they cannot stand still. The bodies of children at this age are flexible and their activity levels are high. Additionally, since large muscle development occurs at a more advanced level than bone development, they could demonstrate locomotor movements in a better way (Çelebi, 2010). Their coordination abilities are highly developed compared to other age groups and they have the ability to combine two or more movements (Mengütay, 2005).

Supporting motor development from early years by including activities that involve motor abilities at home and at preschoolswould ensure that the children have healthy body structures in the future. This is also important in terms of contributing to other developmental areas of children (Çoban \& Nacar, 2006; İnan, 2013; Pedük, 2011; Saracho, 1996). In addition, Sun, Zhu, Shih, Lin, and Wu (2010) demonstrated in their study that motor competence played a major role in child development, motor abilities of children aged between 3-6 improved with age and that children with developmental deficiencies had also deficiencies in motor abilities. 
Due to the fact that 4-6 years refers to the period when the children attain certain abilities, the preschool period is a critical one. In this period, development of motor abilities in children increases as they learn abilities such as running, jumping and bouncing. It is very important to provide supplementary education to children while acquiring these abilities (Gallahue, Ozmun \& Goodway, 2012). These abilities are permanently used throughout life and play a key role in learning new abilities. This period can be expressed as a systematic and programmed education process that helps to reveal the talents and abilities that exist in children. This situation supports the individual differences in children and supports their adaptation to the society. However, if children are not given the opportunity to move and try new abilities, their motor ability performances could be affected negatively.

As stated above, children need areas where they can move and try their motor abilities to ensure that they develop their motor abilities and learn new abilities. The aim of the study, which was conducted in the light of the view that the areas for movement were limited and there were very few areas where children could implement and try these abilities, was to provide basic data for identifying the motor ability in preschool children as well as observing their health and motor development in more detail.

\section{Method}

\subsection{Participants}

The study was participated by a total of 46 children, being 22 girls and 24 boys aged between 5-6, who received preschool education in a private preschool. The heights of the children were determined with a tape measure fixed on the wall; and, their body weights were measured with an electronic precision scale. The KiMo test, which was used for 3-6 years old preschool children in determining the motor ability levels, consisted of 5 subtests. These were the shuttle run (SR), standing long jump (SLJ), one leg stand (OLS), flexibility (F) and lateral jumping (LJ) tests (Klein, Koch, Dordel, Strüder, \& Graf, 2012). These tests measured the abilities of children in terms of balance, strength endurance, coordination, speed, speed strength and flexibility. All tests were practically explained to children before starting the measurement. Before the tests were applied, necessary permissions were obtained from the preschool administration and the families of the children.

\subsection{Kindergarten Mobile Test (KiMo)}

\subsubsection{Shuttle Run (SR)}

$30 \times 30$ squares are fixed on the ground with tape on both ends of the $4 \mathrm{~m}$-distance. One of them is the starting point. In the other square $(3.8 \times 3.8 \times 3.8 \mathrm{~cm})$ two small boards are placed. With the initiation of the time, the child takes the boards in the square on the other side into the square at the starting point one by one. The total the duration of the $16 \mathrm{~m}$ run of the child is included in the study. In this test, it is not allowed to drop the piece of wood.

\subsubsection{Standing Long Jump (SLJ)}

The child tries to jump as far as possible from the starting point by using the arms with both feet closed and knees bent. Landing should be done on both feet without falling to the ground. The distance between the starting point and the heels is measured. This test is repeated twice and the best score is included in the study. During the test, jumping at a distance by accelerating and falling forward or backward after the jump it is considered an error.

\subsubsection{One Leg Stand (OLS)}

Children are expected to stand still for 60 seconds on a purpose-built balance board $(38 \times 4.5 \times 5 \mathrm{~cm})$. The child determines his fixed foot himself and the other foot is lifted sideways. The arms should be in the position opened to the sides. If the child loses his balance, he can touch his foot in the ground. In the measurement, the number of foot contacts with the ground is recorded. If the number of the foot contact on the ground exceeds 30 , the test is completed and written on the test form as 31 . During the test, the foot in the air should be kept in a free state; it should not lean on anything.

\subsubsection{Flexibility (F)}

In the Sit and Reach test, measurements are made with bare feet. $(55 \times 32 \times 31 \mathrm{~cm})$ The point where the foot soles reach is the " 0 " point. The side that reaches the upper part of the legs indicates the negative "--" and the other side beyond the soles indicates the positive "+" values. Before the test, the children were asked to stretch with both hands to the furthest point they could reach without any warm-up. During the movement, the knees should not be bent and should be waited for at least 2 seconds at the most advanced point that can be reached. 


\subsubsection{Lateral Jumping (LJ)}

Over a two-centimeter high $(60 \times 100 \times 2 \mathrm{~cm})$ obstacle in the middle, the child should jump to the sides as fast as possible with bth feet closed. This test is repeated in two 15-second steps. A 1-minute rest is given between repetitions. The total jump values of both are included in the study.

\subsection{Evaluation of the Test}

Motor ability levels of children are classified using age and gender-specific standards set by Klein (2011). Accordingly, it is evaluated according to the norm data determined within 6-month intervals. Evaluation is scored with a grading system from 1 to 6.1 is determined as the best and 6 as the worst. Norm data table is available at www.fitnessolympiade.de.

\subsection{Statistical Analysis}

Descriptive statistics were used to identify the average, frequency and percentage distributions regarding the motor abilities of the children.

\section{Results}

Table 1. Statistical analysis of the descriptive characteristics of the participants

\begin{tabular}{llllll}
\hline Faktor & $\mathrm{N}$ & $\bar{x}$ & $\mathrm{~S}$ & Min. & Max. \\
\hline Age (years) & 46 & 5.22 & 0.42 & 5 & 6 \\
Height $(\mathrm{cm})$ & 46 & 1.03 & 0.06 & 0.91 & 1.15 \\
Weight $(\mathrm{kg})$ & 46 & 19.72 & 3.19 & 15.2 & 29.1 \\
BMI $\left(\mathrm{kg} / \mathrm{m}^{2}\right)$ & 46 & 18.57 & 2.30 & 15.19 & 26 \\
\hline
\end{tabular}

According to the age of all children participating in the study $(x=5.22)$, Neyzi et al. (2008) considering the reference values of Turkish children, height $(\mathrm{x}=1.03 \mathrm{~m})$ and weight $(\mathrm{x}=19.72 \mathrm{~kg})$ values were average values. BMI $(x=18.57)$ values were in normal weight.

Table 2. Descriptive statistics of the measurement values according to the age variable of the participants

\begin{tabular}{lllllll}
\hline Age & Measurements & $\mathrm{N}$ & $\bar{x}$ & $\mathrm{~S}$ & Min. & Max. \\
\hline 5-year & Shuttle Run (s) & 16 & 10.13 & 0.71 & 8.89 & 11.58 \\
& Standing Long Jump (cm) & & 83.75 & 15.06 & 62 & 108 \\
& Flexibility (cm) & & -0.44 & 7.55 & -16 & 15 \\
& One Leg Stand & & 6 & 5.05 & 1 & 15 \\
& Lateral Jumping & & 21.81 & 9.79 & 6 & 36 \\
5.5 -year & Shuttle Run (s) & 20 & 9.97 & 0.98 & 8.26 & 12.28 \\
& Standing Long Jump (cm) & & 81.25 & 13.95 & 55 & 102 \\
& Flexibility (cm) & & -0.70 & 6.02 & -11 & 9 \\
& One Leg Stand & & 7.3 & 7.78 & 1 & 31 \\
& Lateral Jumping & & 24.55 & 5.99 & 11 & 35 \\
6-year & Shuttle Run (s) & \multirow{2}{*}{10} & 10.14 & 1.26 & 8.16 & 12.17 \\
& Standing Long Jump (cm) & & 87.80 & 22.35 & 55 & 123 \\
& Flexibility (cm) & & 0.40 & 4.55 & -8 & 6 \\
& One Leg Stand & & 6.2 & 4.78 & 0 & 13 \\
& Lateral Jumping & & 27.80 & 12.14 & 15 & 54 \\
\hline
\end{tabular}

When the measurement values of the children participating in the study were analyzed, it was seen that the children in the 5 and 5.5 age group had average and below average values according to the norm data in all tests. At the age of 6, it was found that they had bad values in shuttle run and flexibility tests, and they had average values in standing long jump, lateral jumping and balance tests. When we look at the total test results of the sampling, $52.2 \%$ had below-average values in the shuttle run, $41.3 \%$ in standing long jump, $54.3 \%$ in flexibility, $32.6 \%$ in balance and $47.8 \%$ in the lateral jump test. 
Table 3. Evaluation results of the participants in the norm data table according to the gender variable

\begin{tabular}{llllllll}
\hline Factor & Group & $\mathrm{N}$ & Shuttle Run & Standing Long Jump & Flexibility & One-Leg Stand & Lateral Jumping \\
\hline Gender & Boys & 24 & $3.50^{*} \pm 1.50$ & $3.21^{*} \pm 1.10$ & $4.21^{*} \pm 1.21$ & $2.58^{*} \pm 1.50$ & $3.87^{*} \pm 1.57$ \\
& Girls & 22 & $3.69^{*} \pm 0.78$ & $3.60^{*} \pm 1.37$ & $4.23^{*} \pm 1.38$ & $2.32 * \pm 0.99$ & $3.41^{*} \pm 1.30$ \\
\hline
\end{tabular}

Note. ${ }^{*}$ Evaluation is made according to the norm data. 1 refers to the best grade; and 6 refers to the worst grade.

When the test results of the children were analyzed, it was seen that both the girls and boys had below average values in all tests except for the balance test.

\section{Discussion}

In this study, which was carried out to determine the motor ability levels of preschool children, it was found that children had average and below average values in all tests. Considering the percentage distribution of the whole group, $52.2 \%$ had values below the average in shuttle run, $41.3 \%$ in standing long jump, $54.3 \%$ in flexibility, $32.6 \%$ in balance and $47.8 \%$ in lateral jump test; and they were insufficient in coordination, strength and speed forms which were among the basic motor abilities. This number was found to be $45 \%$ when the total score of the KMS test applied to German children aged 3-6 was evaluated (Toia et al., 2009). Motor ability levels of a total of 1228 (563 girls, 665 boys) particpants, whose average age was 4.7, were determined according to their BMI values with the KMS test; as a result, it was found that their motor ability levels were below average. In a similar study, Klein et al. (2010) found that the motor ability levels of the children were below average (Klein et al., 2010). The results of the studies mentioned above were similar to the results of our study since the children who participated in the study were spending most of their time in preschools and were not exposed to extra interventions that would improve their motor abilities during this time like the children in our study.

Greier, Brunner and Riechelmann (2013) examined the relationship between the size of the cities the children lived in and their motor abilities in their study on a total of 1,063 children from 41 kindergartens (4-5 years) in Tyrol, Austria. As a result of the study, it was determined that the children in rural areas had the highest motor ability scores, whereas the motor abilities of the children residing in developed areas were lower. At the end of the study, Greier (2013) stated that insufficient motor abilities of children in developed countries stemmed from lack of exercise, children who attended preschool should be encouraged for physical activities particularly in urban environments, and that appropriate conditions should be created in order that to be ensured. The fact that the children in our country had motor ability levels of below the average was considered as a natural consequence of the condition that the movement areas of children in the urban environment were extremely limited and insufficient in our country.

In another study, Graf and Klein (2011) determined the motor abilities of children between the ages of 3-6 by using KiMo test in 27 preschools (1050 children: 688 experiments, 362 controls). The families of the children in the treatment group were informed about the regulation of nutrition, physical activity and life habits for their children. After 6 months, the motor abilities of the children were re-assessed; although there was no significant change in the control group, the children in the treatment group displayed improvement in the shuttle run (-0.9 seconds), standing long jump $(12 \mathrm{~cm})$, lateral jumping $(4.5$ times), flexibility $(0.7 \mathrm{~cm})$ and one leg stand tests $(-1.7$ contact $)$ tests.

There was no study conducted with the KiMo test at the national level; however, among the tests carried out on children in the same age group, Ulutaş, Demir and Yayan (2017) applied a training program involving the use of fine motor abilities in the preschool children ( 25 experimental and 25 control groups) aged between 5-6 and analyzedthe effects of that training on the development of coarse and fine motor developments. As a result, a significant increase was found in both the coarse and fine motor developments of the children participating in the training program. According to the results of the TGMD2 test used in determining the motor ability levels of 66 preschool children, İri (2018) determined that only one child had superior abilities and the majority of the children had average motor abilities. In their study, where they examined the effects of physical education and sports activities on basic movement abilities, Yavuz and Özyürek (2018) concluded that physical education activities were effective in developing movements in 40 preschool children (20 treatment, 20 control groups) aged between $4-6$.

In the studies mentioned above, it was seen that the motor abilities of the children were improved with the help of the programs implemented. Considering this situation, it can be said that if the children get the chance to become more active with physical activities or games, their basic motor abilities could develop. In addition, it is thought that particularly the preschool institutions should organize activities where children could run and play outdoors in order to ensure energy consumption as well as physical development. 


\section{Conclusion and Recommendations}

As a result of the developing technology, children spend most of their time with tools such as television, telephone and tablet. This reduces the physical activity requirements of children. Physical activity and exercise play an important role for the physical, mental and social development of children in a holistic perspective. Considering that the motor abilities of children have a positive relationship with physical activity, it is a natural consequence of the insufficient amount of activities involving coarse motor abilities in a limited space at preschools as well as the less active states of children in terms of their life styles. Therefore, it is necessary for both schools and parents to create environments and opportunities where children could move and play.

\section{Acknowledgement}

I would like to thank the children, their families, the preschool administration and teachers who participated in the measurements for the research.

\section{References}

Çelebi, B. (2010). Effects of movement education on physical and motor developments between 5 and 6-year-old-children in preschool. Unpublished master thesis, MuğlaUniversity, Social Sciences Institute, Muğla.

Çoban, B., \& Nacar, E. (2006). Educational games in preschool education. Ankara: Nobel Publishing.

Gallahue, D., \& Cleland-Donnelly, F. (2007). Developmental physical education for all children (p. 4). Champaign, IL: Human Kinetics.

Gallahue, D. L., Ozmun, J. C., \& Goodway, J. D. (2012). Understanding motor development: Infants, children, adolecents, adults (7th ed.). USA: McGraw Hill.

Graf, C., \& Klein, D. (2011). Bewegungbei Vorschulkindern: Empfehlungen und Wirklichkeit. Austrian Journal of Clinical Endocrinology and Metabolism, 4(2), 16-20.

Greier, K., Brunner, F., \& Riechelmann, H. (2013). Wohnortgröße und Motorische Leistungsfähigkeit von Kindergartenkindern. German Journal of Sports Medicine, 64(10), 301-306. https://doi.org/10.5960/dzsm.2012.075

Haywood, K. M., \& Getchell, N. (2014). Life span motor development (6th ed.). USA: Human Kinetics.

İnan, H. Z. (2013). Physical and motor development in preschool period. İn B. Akman (Ed.), Development in Early Childhood. Ankara: Nobel Academic Publishing.

İri, R. (2018). Determination of Motor Development Levels in Preschool Children. 16. Sports Sciences Congress, Turkey. Summary report.

Klein, D. (2011). Bewegungs- und gesundheitsförderung in kindergarten wirkungs analyse ausgewählterkölner interventionen. Doktoratezi, Deutsche Sporthochschule, Köln.

Klein, D., DeToia, D., Weber, S., Wessely, N., Koch, B., Dordel, S., ... Graf, C. (2010). Effects of a low threshold health promotion intervention on the BMI in pre-school children under consideration of parental participation. The European e-Journal of Clinical Nutrition and Metabolism, 5, e125-e131. https://doi.org/10.1016/j.eclnm.2010.03.002

Klein, D., Koch, B., Dordel, S., Strüder, H., \& Graf, C. (2012). The KiMo Test: A motor screening for pre-school children aged 3-6 years. Submitted.

Mengütay, S. (2005). Movement development and sports in children. İstanbul: Morpa Culture Publications.

Neyzi, O., Günöz, H., Furman, A., Bundak, R., Gökçay, G., Darendeliler, F., \& Baş, F. (2008) Body weight, height, head circumference and body mass index reference values in Turkish children. Journal of Child Health and Diseases, 51, 1-14

Payne, V. G., \& Isaacs, L. D. (2016). Human motor development: A lifespan approach (9th ed.). USA: Routledge. https://doi.org/10.4324/9781315213040

Pedük, Ş. (2011). Psychomotor development. In N. Aral \& G. Baran (Eds.), Child development. İstanbul: YaPa Publications.

Saracho, O. N. (1996). The relationship between the cognitive style and play behaviors of 3 to 5 -year-old children. Personality and Individual Differences, 21(6), 863-876. https://doi.org/10.1016/S0191-8869(96)00152-3 
Stodden, D. F., Goodway, J. D., Langendorfer, S. J., Roberton, M. A., Rudisill, M. E., Garcia, C., \& Garcia, L. E. (2008). A developmental perspective on the role of motor ability competence in physical activity: An emergent relationship. Quest, 60(2), 290-306. https://doi.org/10.1016/S0191-8869(96)00152-3

Sun, S. H., Zhu, Y. C., Shih, C. L., Lin, C. H., \& Wu, S. K. (2010). Development and initial validation of the preschooler gross motor quality scale. Research in Developmental Disabilities, 31, 1187-1196. https://doi.org/10.1016/j.ridd.2010.08.002

Toia, D. D., Klein, D., Weber, S., Wessely, N., Koch, B., Tokarski W., ... Graf, C. (2009). Relationship Between Anthropometry and Motor Abilities at Pre-School Age. The European Journal of Obesity, 2, 221-225. https://doi.org/10.1159/000228155

Ulutaş, A., Demir, E., \& Yayan, E. H. (2017). The Effect of the Motor Development Training Program on Rough and Fine Motor Development of Five-Six-Year-Old Children. Abantízzet Baysal University Journal of Education Faculty, 17(3), 1523-1538. https://doi.org/10.17240/aibuefd.2017.17.31178-338846

Yavuz, N. F., \& Özyürek, A. (2018). Effects of Physical Education and Sport Activities on Motor Abilities of Preschool Children. Karaelmas Journal of Educational Science, 6, 40-50.

\section{Copyrights}

Copyright for this article is retained by the author, with first publication rights granted to the journal.

This is an open-access article distributed under the terms and conditions of the Creative Commons Attribution license (http://creativecommons.org/licenses/by/4.0/). 